C O

\title{
O FUNDO SETORIAL DO AUDIOVISUAL E AS POLÍTICAS AUDIOVISUAIS: INTERFACES COM OS ESTUDOS DE CULTURA VISUAL
}

Audiovisual Sectorial Fund and audiovisual policies: interfaces with visual culture studies

Fondo Sectorial Audiovisual y politicas audiovisuales: interfaces com los estúdios de cultura visual

\author{
LIA CALABRE ${ }^{1 *}$ \\ THIAGO DA SILVA TAVARES ${ }^{I * *}$
}

DOI: https://doi.org/10.1590/S2178-149420210110

Programa de Pós-Graduação em Memória e Acervos - Fundação Casa de Rui Barbosa, e Programa de Pós-Graduação em Cultura e Territorialidades, Universidade Federal Fluminense - Niterói (RJ), Brasil.

*Doutora em História pela Universidade Federal Fluminense (liacalabre@gmail.com).

(D) https://orcid.org/0000-0002-7586-7210

"Universidade Federal Fluminense - Niterói (RJ), Brasil.

**Mestre em Cultura e Territorialidades (thiago.svtavares@gmail.com).

(D) https://orcid.org/0000-0003-0409-131X

Artigo recebido em 23 de agosto de 2020 e aprovado para publicação em 11 de novembro de 2020. 


\title{
RESUMO
}

Contemporaneamente, a produção audiovisual cumpre destacado papel na composição do campo da cultura visual. Assim, consideramos a dimensão das políticas públicas como elemento fundamental na composição da produção visual, na medida em que são elas que organizam os modos de produção, circulação e distribuição desse campo. 0 presente artigo elabora uma radiografia da política cultural para o audiovisual do Brasil no período histórico que compreende os anos entre 2006 e 2018. A metodologia pautou-se pela análise qualitativa e quantitativa dos dados de desempenho de mercado disponibilizados pela Agência Nacional do Cinema, bem como das leis e documentos oficiais.

PALAVRAS-CHAVE: Política Audiovisual; Política Cultural; Fundo Setorial do Audiovisual; Cultura Visual.

\begin{abstract}
Contemporaneously, audiovisual production plays an important role in the composition of the visual culture field. Thus, we consider the dimension of public policies as a fundamental element in the composition of visual production as they are the ones that organize the modes of production, circulation, and distribution in this field. This article elaborates an X-ray of the cultural policy for audiovisual in Brazil in the historical period from 2006 to 2018. The methodology started from the qualitative and quantitative analysis of the market performance data provided by Agência Nacional do Cinema, as well as the laws and official documents.
\end{abstract}

KEYWORDS: Audiovisual Policy; Cultural Policy; Audiovisual Sectorial Fund; Visual Culture.

\section{RESUMEN}

La producción audiovisual contemporánea juega un papel importante en la composición del campo de la cultura visual. Así, consideramos la dimensión de las políticas públicas como un elemento fundamental en la composición de la producción visual ya que son las que organizan los modos de producción, circulación y distribución en este campo. Este artículo elabora una radiografía de la política cultural del audiovisual en Brasil en el período histórico entre 2006 y 2018. La metodología partió del análisis cualitativo y cuantitativo de los datos de desempeño de mercado proporcionados por Agência Nacional do Cinema, así como las leyes y documentos oficiales.

PALABRAS CLAVE: Política Audiovisual; Política Cultural; Fondo Sectorial Audiovisual, Cultura Visual. 


\section{INTRODUÇÃO}

intenção do presente artigo é a de analisar o campo do audiovisual, usando os pro-
cessos exteriores ao produto fílmico, que é riquíssimo e determinante para que os pressupostos estéticos tomem corpo. Para que os filmes, as séries, as produtoras e as salas de cinema existam, é fundamental que haja um procedimento político que contribua para sua organização e funcionamento. Contemporaneamente, a produção audiovisual cumpre destacado papel na composição do campo da cultura visual. Assim, consideramos a dimensão das políticas públicas como elemento fundamental na composição de tal universo.

0 conjunto dos produtos que compõem o campo do audiovisual é parte significativa daquele que conforma o universo da cultura visual. Os estudos e as reflexões acerca das políticas públicas para o audiovisual têm muito a contribuir para o desenvolvimento dos trabalhos do campo da cultura visual, pensando esta última como uma tendência moderna de se visualizar a existência. Como afirma Rosana Horio Monteiro: "o termo cultura visual pode englobar uma variedade de formas de representação, desde as artes visuais e o cinema, até a televisão e a propaganda [...]. A cultura visual se ocupa da diversidade do universo de imagens" (Monteiro, 2008: 131). Os estudos sobre práticas culturais no Brasil informam-nos que o equipamento cultural mais presente na vida das pessoas é a televisão. Ela chega hoje a $100 \%$ das residências servidas de energia elétrica. É pelos canais de televisão (aberta e/ou paga) que circula parte significativa da produção audiovisual mundial.

A primeira década do século XXI faz surgir um movimento de centralidade do mercado audiovisual nas dinâmicas da sociedade contemporânea. Isso, em parte, por conta das transformações tecnológicas ocorridas durante o período, em parte por conta do papel cada vez mais central que a linguagem audiovisual vem ganhando nas dinâmicas sociais do globo'. Muitas das ideias e das formas de estar no mundo contemporâneo são fruto das nossas experiências visuais que, em última instância, conformam as tendências da nossa visualização da existência humana. Como nos alerta Mirzoeff, a vida moderna desenvolve-se nas telas. Segundo o autor, no fim dos anos 1990 e início da década de 2000, um norte-americano adulto permanecia uma média de quatro horas diárias em frente à tela da televisão e essa prática já sofria a concorrência dos meios visuais presentes na internet. Ainda segundo o autor: "Nessa espiral imaginária, ver é mais importante que crer. Não é uma mera parte da vida cotidiana, senão a vida cotidiana em sim mesmo" (Mirzoeff, 2003: 17).

As disputas e as tendências, políticas e econômicas, que atravessam os processos de regulação do sistema de produção audiovisual nos fornecem elementos adicionais para a compreensão dessa espiral imaginária no campo de estudos da cultura visual. Foi nesse sentido que o presente artigo foi construído. 
0 audiovisual é um setor considerado complexo, pois a base de segmentos produtivos contempla as diversas linguagens que ele possui: cinema, televisão ${ }^{2}$, games e, mais recentemente, o streaming. Logo, a indústria audiovisual compreende diversas "pequenas indústrias". Todas essas formas do fazer audiovisual estão enquadradas e organizadas numa configuração com variados agentes produtivos. A leitura setorial que fazemos desse campo compreende uma dinâmica que se dá pelo reconhecimento da distinção entre as atividades desempenhadas pelos diversos agentes econômicos.

No campo da política audiovisual, fica patente que o investimento massivo somente na produção do conteúdo audiovisual em si não é capaz de trazer o assentamento econômico propício à configuração de uma indústria audiovisual brasileira sustentável ${ }^{3}$. Portanto, torna-se necessário que as políticas audiovisuais formulem ações que promovam a interlocução efetiva dos agentes nacionais nesse setor, que faz parte daqueles que interferem nas formas de ver e significar contemporaneamente a sociedade. Soma-se a isso a necessidade cada vez maior de uma política específica para a atividade, que dê conta das suas novas dimensões. Nesse sentido, o entendimento setorial do audiovisual não só lança luz sobre o campo como força produtiva e inovadora, mas também cria a necessidade de um conhecimento do audiovisual como um sistema, que contém produtos e agentes com contínuas relações mercadológicas e não mercadológicas para a criação, produção e venda dos produtos audiovisuais, que cumprem um papel fundamental na construção do campo do simbólico.

\section{UMA POLÍTICA SETORIAL PARA AS CULTURAS (AUDIO)VISUAIS}

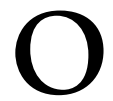

modelo de fundo setorial surge no Brasil num contexto de fortalecimento da capacidade de pesquisa, de desenvolvimento e de inovação do país. Os Fundos são entendidos como fontes complementares de recursos para setores considerados pelo Estado como estratégicos para o desenvolvimento econômico. Suas receitas são oriundas de contribuições incidentes sobre o resultado da exploração de recursos naturais, como porcentagem do Imposto sobre Produtos Industrializados e da Contribuição de Intervenção no Domínio Econômico (Cide).

0 modelo de gestão baseia-se na existência de Comitês Gestores, responsáveis por definir as estratégias, rumos, ações, programas e planos de investimentos futuros, integrando a participação de vários setores da atividade e possibilitando a gestão compartilhada das decisões de desenvolvimento.

Segundo a Financiadora de Estudos e Projetos (Finep), os Fundos possuem características básicas quanto à sua operacionalização: vinculação obrigatória de receitas ao setor 
a que se destina, configuração de ações e projetos com prazos maiores ao período de exercício fiscal, caráter compartilhado da gestão (Comitê Gestor contendo agentes dos diversos segmentos do setor), caráter diversificado da fonte de receitas (contribuição dos diferentes agentes econômicos e de diferentes receitas) e, por fim, programas e ações que integrem toda a cadeia produtiva em um mesmo plano (Finep, 2016).

0 surgimento dos fundos setoriais (FS) no Brasil dá-se nos anos 1990, quando se implementa um novo instrumento de política científica e tecnológica no país. 0 que se percebia era que o setor de ciência e tecnologia tinha um fluxo de financiamento inconsistente, que não era abrangente, não contemplava agentes fundamentais do processo tecnológico, nem era eficiente em sua operacionalização. Quanto à atuação do Estado, este jamais se mostrou suficientemente atento às carências desse setor.

\section{O FUNDO SETORIAL DO AUDIOVISUAL}

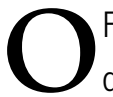
Fundo Setorial do Audiovisual (FSA) surge com as disposições da primazia do Fundo Nacional de Cultura (FNC) como indutor do desenvolvimento do setor cultural no país. Com base no olhar setorial para a cultura, inaugura-se outra tratativa para a política desse setor. As premissas buscadas para a construção dessa política guardam influência da construção dos fundos setoriais já existentes no Brasil. É o que Rosana Alcântara, que atuava como diretora da Agência Nacional do Cinema (Ancine) à época da construção do Fundo e que foi uma das suas mentoras, admite:

Na Ancine, nós começamos a estudar um pouco as estruturas existentes no Estado no campo das subvenções. Nós encontramos, nos sistemas de Ciência Tecnologia e Inovação (CT\&l), mecanismos já formatados e ligados à FINEP, que são os fundos setoriais. $\mathrm{Na}$ época, nós entrevistamos, por exemplo, o secretário executivo do Ministério da Ciência e Tecnologia e as pessoas responsáveis pelos fundos para conhecer mais sobre eles. Descobrimos que havia os fundos transversais, específicos e setoriais e cada um deles tinha uma lei específica. Desde o governo [Fernando Henrique Cardoso] FHC, havia um entendimento de que não se construiriam mais fundos novos. A partir disso, nós começamos a ver a possibilidade de começar a utilizar as estruturas de fundos já existentes. (Alcântara, entrevista, 2020).

O FSA acaba por ser a ação que inaugura a nova estratégia do Ministério da Cultura (MinC), atuando de forma mais indutiva. O Fundo articula duas dimensões: o incremento de valores financeiros e o fomento ao setor. Na prática, trata-se de uma alternativa ao modelo de leis de incentivo, do fomento indireto e da participação tangenciada do Estado na cultura. É a configuração de um plano de atividades e ações organizado, que visa ao desenvolvimento 
do setor como um todo, não ancorado apenas numa política de "projeto a projeto" que as leis de inventivo trazem.

O FSA foi instituído pela Lei n 11.437, de 28 de dezembro de 2006, e regulamentado pelo Decreto $n^{\circ}$ 6.299, de 12 de dezembro de 2007. Representa, ao mesmo tempo, uma alteração na Medida Provisória n 2.228-1 e uma ampliação da política para o setor. Em seu primeiro artigo, estabelece que o montante dos recursos da Contribuição para o Desenvolvimento da Indústria Cinematográfica Nacional (Condecine), que havia sido criada pela Medida Provisória $n^{\circ}$ 2.228-1/2001, será destinado ao FNC e caracterizado institucionalmente como "categoria específica". É importante salientar que essa opção pela criação do fundo setorial via Fundo Nacional representa uma alternativa da gestão federal para redimensionar a importância do FNC como política de fomento, conferindo-lhe um lugar cada vez mais central na política cultural do período.

0 ministro Juca Ferreira, quando da apresentação do lançamento do FSA em 2008, afirmou que:

O Fundo Setorial do Audiovisual é o primeiro dos fundos setoriais que pretendemos pôr em operação no FNC. 0 modelo da sua atuação, combinando gestores públicos e representantes do setor; os mecanismos de financiamento diversificados e a capacidade de atuar nos diversos elos da cadeia são características da mudança de paradigma que pretendemos para o financiamento da cultura no Brasil. (Brasil, 2008: 1).

Torna-se preciso compreender igualmente em que consiste o conteúdo financeiro do FSA. Apesar de a Lei n 11.437 prever um leque variado de receitas, é a cobrança do Condecine que representa o maior montante de alimentação do fundo. A espécie tributária prevista na Constituição e designada como Cide é um tributo de competência exclusiva da União, usado como mecanismo de intervenção do Estado em dado setor econômico e cuja totalidade da arrecadação já possui uma destinação predefinida. Além disso, ele é de natureza "extrafiscal, ou seja, não se destina a suprir os cofres públicos de recursos financeiros como os tributos de arrecadação fiscal" (Martins, 2009: 157).

A criação da Condecine deu-se com o entendimento de que o setor audiovisual, para desenvolver-se, precisava criar maneiras de integralizar-se do ponto de vista do fomento das ações de desenvolvimento. Para compreender a própria criação do FSA é necessário retornar a 2001, quando se vislumbra um esgotamento do modelo de leis de incentivo proposto nos anos 1990 em substituição à Embrafilme. Naquele momento, as leis de incentivo eram a única alternativa de formulação de negócios para o setor audiovisual. Outro dos debates imperativos que se impunham à corporação era sobre a transformação estrutural da configuração econômica do setor. 
Sobre a Condecine, cabe considerar que a medida provisória esclarece que a contribuição é gerada pela "veiculação, produção, licenciamento e distribuição de obras cinematográficas e vídeo-fonográficas com fins comerciais, por segmento de mercado a que forem destinadas" (Medida Provisória n².228-1, cap. VI, art. 32, 2001). Essa medida tem em seu cerne justamente a participação de agentes outros do mercado, pois impacta não só a veiculação de obras nas salas de exibição, mas todo produto audiovisual difundido nos meios disponíveis no mercado audiovisual brasileiro. Tal configuração afeta diretamente as chamadas majors, as exibidoras e as programadoras do segmento de televisão e, posteriormente, com as reconfigurações do mercado ocasionadas pela Lei $n^{0} 12.485$, as empresas de telefonia - as chamadas teles, muitas delas subsidiárias de empresas internacionais.

Nesse sentido começam a se desenhar, objetivamente, ações para resolver a reivindicação clássica dos realizadores da participação estratégica do segmento televisivo, não apenas na veiculação das obras, mas também contribuindo financeiramente para o desenvolvimento do setor.

A configuração da Condecine, portanto, é um agrupamento de três Cide divididos da seguinte forma:

1. Condecine-Título: que incide sobre a comercialização das obras audiovisuais publicitárias e não publicitárias nos diferentes segmentos de mercado do audiovisual;

2. Condecine-Remessa: incide sobre os agentes que pagam os rendimentos referentes à exploração financeira de obras audiovisuais no exterior;

3. Condecine-Teles: incide sobre os provedores de serviços de telecomunicações autorizados a distribuir o conteúdo na forma de serviço de acesso condicionado.

Com a Medida Provisória n².228-1/2001, a política audiovisual amadurecia o ideário setorizado e abria o caminho argumentativo (mas também normativo) para a construção do FSA. 0 artigo da referida medida provisória proporcionava um respaldo que possibilitava a ampliação dos recursos no futuro. Ao expandir os segmentos econômicos do audiovisual para além das salas de exibição, a medida provisória construía todo um vetor financeiro que seria a base para a configuração da nova matriz econômica do audiovisual brasileiro.

Retomando a análise da lei, percebe-se claramente um entendimento de que a política para o setor deve se construir não mais sobre a lógica do fomento, mas sobre a lógica de investimento econômico, em que se busca o retorno ou o benefício sobre o investimento inicial.

Carlos Augusto Calil, em entrevista à pesquisadora Ana Paula da Silva e Sousa, afirma que o FSA de fato representou uma guinada no mercado, colocando a política audiovisual em outro lugar de atuação. Segundo ele: 
Qual o principal erro da Lei do Audiovisual? Ela investe em filmes e não numa produtora que tem uma carteira de projetos ou num distribuidor. Investir em uma obra é como jogar na roleta num número só. Só o conjunto é capaz de proteger o investimento. A política do caso a caso, que era também o que acontecia na Embrafilme, é uma política equivocada. [...] No Brasil, até o Fundo Setorial, o incentivo fiscal ia para uma obra; e se essa obra não der retorno nenhum, o produtor não tem que ressarcir nada para o Estado. 0 Fundo Setorial recupera a ideia de empresas e a ideia de se retornar valores para o fundo comum. Esse retorno ainda é muito modesto, mas já é muito melhor do que a lei do Audiovisual. O Fundo Setorial é um caminho conservador, mas é um caminho seguro, enquanto a Lei do audiovisual é uma liberalidade (Calil apud Souza, 2018: 168).

Podemos acrescentar ainda que, apesar de o FSA buscar uma postura empreendedora por meio da celebração do resultado financeiro, da capacidade de gestão e da idoneidade fiscal das empresas produtoras, o fundo também tem por objetivo que os projetos apresentem resultado artístico. O FSA, portanto, interessa-se, ao investir no setor, por um duplo resultado: financeiro, com predileção pelo investimento com capacidade de lucro, e artístico, com obras que tenham inserção em festivais internacionais e promovam a produção nacional, trazendo- Ihe prestígio, e o mercado brasileiro no mundo.

0 decreto de criação do FSA aponta-nos caminhos que revelam que o DNA do pensamento setorial desenvolvido pela corporação audiovisual está presente. Seu conteúdo contém características que mostram o intuito de promover ações que impactam as estruturas do setor. Destacamos 0 artigo $4^{\circ}$ da Lei $n^{0} 11.437$, no qual vemos que a destinação dos recursos do FSA se ramifica em três programas:

1. Programa de Apoio ao Desenvolvimento do Cinema Brasileiro (Prodecine);

2. Programa de Apoio ao Desenvolvimento do Audiovisual Brasileiro (Prodav);

3. Programa de Apoio ao Desenvolvimento da Infraestrutura do Cinema e do Audiovisual (Proinfra).

São três programas voltados aos segmentos considerados como economicamente centrais da atividade.

Nesse sentido, a construção legal do FSA indica-nos que a política audiovisual conseguiu construir um caminho para promover o desenvolvimento integrado/articulado do setor. Segundo Rosana Alcântara: "Para poder almejar uma capacidade mais industrial, era preciso investir nas suas diversas cadeias, de ponta a ponta, era necessário que houvesse uma fonte de recursos alavancadora desse processo" (Alcântara, entrevista, 2020). 0 Fundo é entendido como o elo que unifica o setor audiovisual em prol de uma mesma 
dinâmica, pois envolve os aspectos criativos e empresariais do setor e o particular-geral das cadeias produtivas.

Entretanto, o viés um tanto economicista dessa política esqueceu-se de alocar investimentos (ou ignorou essa possibilidade) a outros elos igualmente fundamentais à atividade audiovisual. Não há menção a investimentos na produção do curta-metragem, que funciona como um treinamento para os sujeitos que atuam profissionalmente no setor ${ }^{4}$. Não há menção, tampouco, a um programa que financie o circuito de festivais de cinema, que operam como vetores de escoamento da produção de curtas e longas-metragens, proporcionando uma janela para a exibição desses trabalhos e a revelação de novos talentos, não só artísticos, mas técnicos, para o setor. Não há menção, igualmente, ao investimento em preservação e restauração de obras audiovisuais ${ }^{5}$.

\section{A LEI DA TV PAGA: CARACTERÍSTICAS DA SETORIALIDADE NA REGULAÇÃO DO SETOR}

m 2011, a presidenta Dilma Rousseff promulga a Lei $n^{0} 12.485$. Mais conhecida como
a Lei da TV Paga, ela teve o papel de atualizar, reformular e ampliar o segmento da televisão paga no Brasil, além de unificar toda a regulamentação vigente até então em um mesmo arcabouço legal, não pelo viés da tecnologia que vigorava anteriormente, mas pelas características do serviço prestado. No espírito dessa nova lei estava a mudança de conceito do segmento, que passou a ser o de serviço de acesso condicionado. A tecnologia utilizada passou então a ser apenas um detalhe em relação à natureza da atividade.

Outro aspecto da lei foi a reestruturação na cadeia de valor do segmento por meio do estabelecimento de cotas de conteúdo brasileiro independente, em cada canal, em duas modalidades: reserva de mercado pelo pacote ofertado e cota de conteúdo por canal. Isso foi importante tanto para o escoamento do conteúdo produzido quanto para a ampliação das possibilidades da entrada da iniciativa nacional em outras instâncias do mercado. Na prática, a lei torna obrigatório que os pacotes contenham um canal brasileiro a cada três estrangeiros, sendo um terço desses canais oriundos de programadora brasileira independente. Dos canais ofertados nos pacotes, dois devem conter doze horas de produção nacional independente e ao menos um não pode ser controlado ou ser subsidiário de empresas de radiodifusão. Tais medidas possibilitaram, a um só tempo, a criação de programadoras independentes brasileiras, a criação de canais independentes sem vínculos societários com outras empresas e canais com maior programação brasileira produzida por empresas produtoras independentes ${ }^{6}$. 
Entretanto, a ação que de fato representou o grande incremento do FSA, ampliando as possiblidades de investimento dessa política, foi a autorização da atuação das empresas de telecomunicações internacionais no mercado da televisão paga.

Ancorada em tais reconfigurações, Ana Paula da Silva e Sousa (2018) afirma que essa articulação para a chegada das teles no mercado de televisão paga viria acompanhada da introdução de recursos oriundos dessas empresas. 0 caminho encontrado pela Ancine para que houvesse tal participação foi o reordenamento fiscal de um imposto já existente - o Fundo de Fiscalização das Telecomunicações (Fistel). Estabeleceu-se que uma porcentagem desse imposto fosse destinada especificamente ao setor audiovisual. Como havia uma integração cada vez mais ativa dos agentes econômicos, com as teles entrando de vez no negócio audiovisual e uma leitura setorializada no campo político, parecia fazer sentido que o fundo originalmente pensado para cobrir ações no campo audiovisual agregasse também essas empresas. Foi criado então, o Condecine-Teles. Isso representou a grande guinada do FSA para se tornar a principal ação setorial de um segmento da cultura brasileira.

\section{BALANÇOS DO PASSADO E O FUTURO DO PRESENTE: O FUNDO SETORIAL DO AUDIOVISUAL ENTRE 2006-2018}

ntes de realizar a análise dos dados relativos à política setorial, há de se ter cuidado
a se conclamar simplesmente a vitória do FSA, pois corre-se o risco de não perceber o que há por trás dos gráficos e dos números crescentes: os pontos fracos, as incapacidades e os limites das ações.

Os dados trabalhados na pesquisa demonstram que há evolução gradual do Fundo nos seus primeiros anos, com valores abaixo dos 100 milhões até 2011. Com a criação do Condecine-Teles, há um crescimento exponencial da arrecadação até resultar em valores acima dos 700 milhões de reais/ano. Não há na história do setor audiovisual valores tão elevados para o financiamento das ações. Percebe-se também que os valores disponíveis se estabilizam em torno do montante de 700/800 milhões de reais/ano, com tendência de queda. Entretanto, os dados aparentes revelam, ao mesmo tempo, um cenário inédito relativo aos valores de investimento no setor e a maior fraqueza do $\mathrm{FSA}^{7}$.

O FSA obteve a arrecadação total de um pouco mais de 6 bilhões durante o período de recorte dos dados. 0 maior montante desse valor é oriundo da incidência da taxação das empresas de telecomunicações. Analisando a porcentagem de valor sobre mesmos dados, observamos o cenário mostrado no Gráfico 1. 


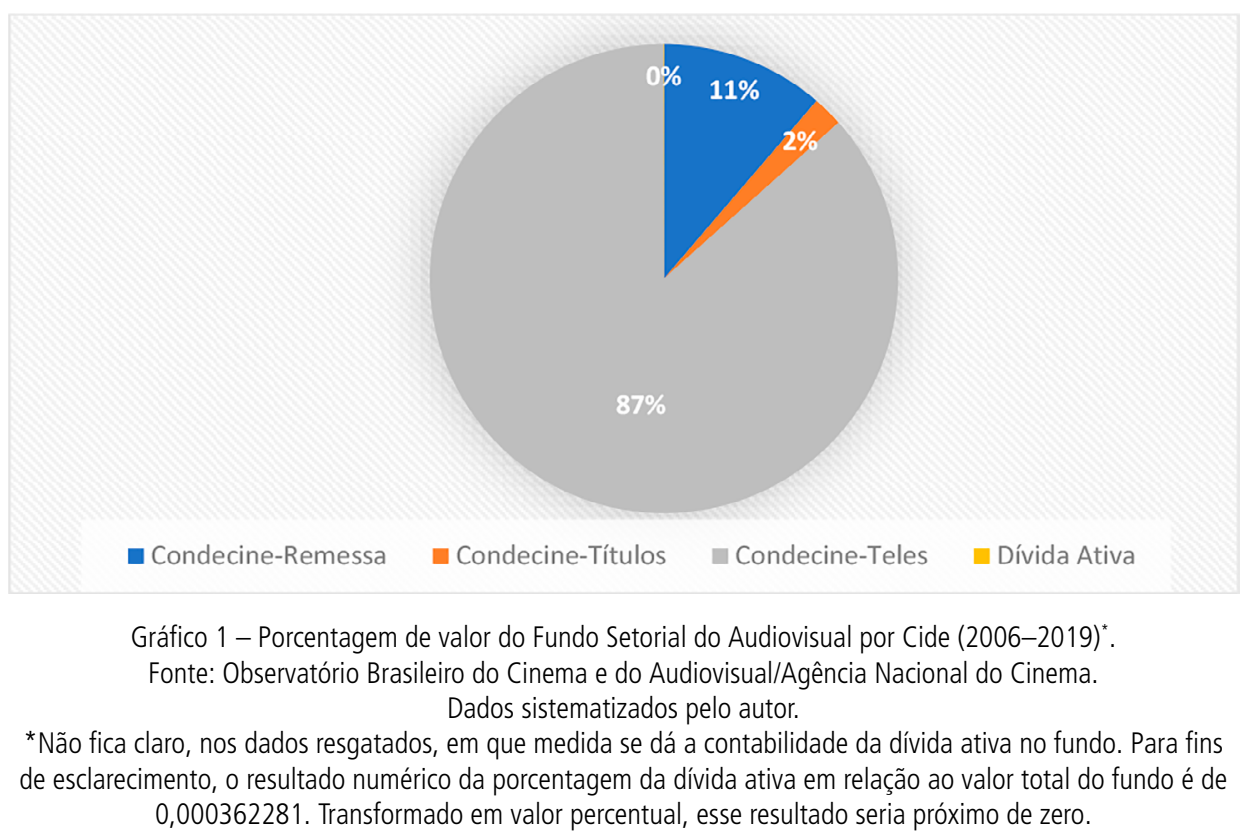

0 Condecine-Títulos, que advém da comercialização efetiva das obras audiovisuais no mercado brasileiro, contribui com apenas $2 \%$ para a arrecadação do FSA. Já a Condecine-Remessa que é, grosso modo, dinheiro estrangeiro, contribui com $11 \%$ para a arrecadação do fundo. 0 montante oriundo da dívida ativa é tão irrisório que percentualmente se aproxima de $0 \%$ de participação. Percebe-se também que o Condecine-Teles compõe a maior fatia de arrecadação do Fundo. Essa contribuição é oriunda das empresas de telecomunicações que, apesar de serem fundamentais para a fruição contemporânea do setor audiovisual, sempre se viram distantes dos benefícios que o Fundo trazia8.

A visão que as teles têm da incidência do Condecine é a de que ela é mais uma oneração para as empresas. Houve até mesmo contestação do recolhimento da contribuição na justiça. Em 2016, o desconforto das teles atingiu seu ápice com o aumento do valor da contribuição $0^{9}$. No momento em que as teles questionaram judicialmente a sua contribuição ao fundo, a fala de Manuel Rangel faz o seguinte alerta:

Nós perderíamos a escala que houve até aqui. [0 não pagamento] vai causar uma interrupção desse círculo virtuoso iniciado com a aprovação da Lei da TV paga, que tem oferecido extraordinários resultados na economia do audiovisual, com crescimento de 8\% ao ano de 2007 a 2013. É um peso significativo. A redução do bolo da CONDECINE significa que a gente vai ter que redimensionar todo o trabalho. E esse mercado vai desacelerar. (Rangel, 2016) ${ }^{10}$. 
Portanto, ao questionar a validade de sua contribuição financeira ao setor, as teles revelam-se ao mesmo tempo como as grandes protagonistas do FSA e os seus maiores algozes. Outro ponto que se deve salientar é que o FSA é alimentado basicamente pelo capital estrangeiro, uma vez que as receitas são oriundas de valores remetidos às empresas no exterior e pelas empresas de telecomunicações, que por sua vez são em grande parte subsidiárias de empresas estrangeiras.

Esses dados mostram que a capacidade de redistribuição de valores também é uma das características do FSA. 0 mecanismo executa uma redistribuição dos recursos dos agentes que detêm uma capacidade maior de angariar recursos, como é o caso das teles, para empresas ou agentes econômicos que são mais frágeis financeiramente e que recebem investimento do Fundo. 0 mesmo se faz notar quanto ao Condecine-Título: a cobrança incidente sobre obras estrangeiras é maior do que aquela que incide sobre obras nacionais.

A política do Fundo apresenta-se como um mecanismo de alta capacidade de investimento pela concentração dos valores oriundos da totalidade do setor, o que facilita também sua capacidade de ter, digamos, uma posição mais central em ações de desenvolvimento setorial. Vejamos o Gráfico 2.

Em perspectiva comparada com os outros mecanismos de investimento público no setor, nota-se que o investimento de recursos oriundos do Fundo está presente em $57 \%$ do total de investimentos durante o período em análise, contra $41 \%$ de recursos oriundos de captação por meio de leis de incentivo. Os recursos advindos "diretamente" do Estado são irrisórios em relação àqueles levantados por outros mecanismos.

Analisando tais dados, constata-se a forte capacidade de arrecadação do FSA em comparação às leis de incentivo, ainda mais ao se vislumbrar um horizonte em que os valores

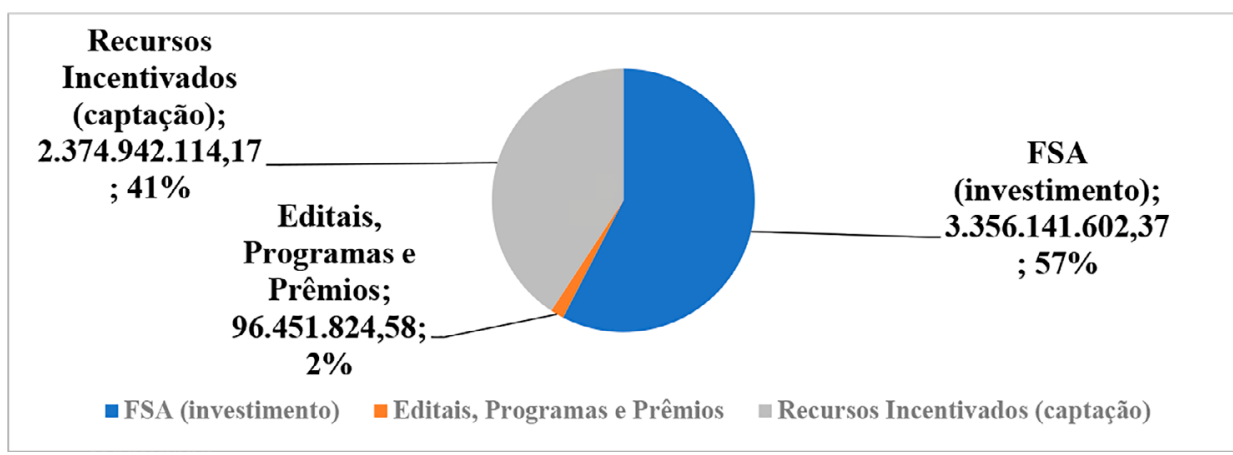

Gráfico 2 - Investimentos Públicos no Setor Audiovisual em milhões (2009-2018) (âmbito federal). FSA: Fundo Setorial do Audiovisual.

Fonte: Observatório Brasileiro do Cinema e do Audiovisual/Agência Nacional do Cinema. Dados sistematizados pelo autor. 
captados pelas leis de incentivo têm como objetivo a produção de longas-metragens e séries e impactam em primeiro plano esse segmento. Já o FSA possui uma característica metodológica mais abrangente, abarcando todo o setor, logo o investimento acaba por trazer resultados mais conectados à cadeia produtiva. Reiteramos que, por mais que as leis de incentivo tenham impacto no setor, isso não representa uma ação sistêmica nem a garantia de sustentabilidade do modelo econômico.

Sobre o impacto da política setorial na infraestrutura da atividade audiovisual, uma das maiores preocupações do setor era a de que os investimentos permitissem que o segmento de exibição voltasse a ter larga penetração territorial ${ }^{11}$. 0 parque exibidor acabou por abandonar as pequenas cidades e o interior do país, concentrando-se nos grandes centros urbanos. Tornava-se necessário, então, que a política audiovisual promovesse uma dupla alavancagem: no número total de salas de cinema e no número de cidades com salas de exibição.

Por meio da ação "Cinema perto de você", a Ancine configurou linhas de crédito para empresas de exibição de médio e pequeno porte, promovendo a redução nos custos de equipamentos, facilitando a atualização tecnológica das salas de cinema, promovendo a chamada digitalização do parque e também a abertura de novas salas (Gráfico 3).

Nota-se o crescimento constante do número de salas no Brasil durante o período. 0 parque exibidor retornou a patamares de 1975 (3.276 salas), ainda que tenha ficado aquém das metas estabelecidas pelo Plano de Diretrizes e Metas. Sobre a dimensão da descentralização do parque exibidor, também fica evidente que os investimentos do Fundo poderiam ter alcançado melhor resultado. Segundo Souza (2018), a região Sudeste, que historicamente tem o maior número de salas, foi a que mais se beneficiou pelo programa, com $28,8 \%$ dos investimentos. Outra questão importante é o processo cada vez maior de intersecção entre a

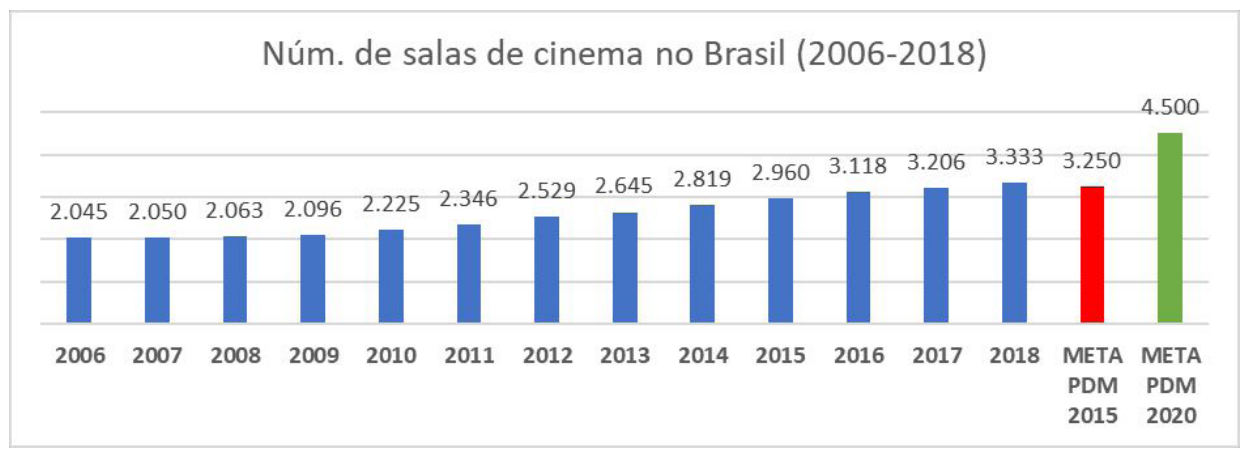

Gráfico 3 - Evolução do Parque Exibidor do Brasil (2006-2018). PDM: Plano de Diretrizes e Metas.

Fonte: Observatório Brasileiro do Cinema e do Audiovisual/Agência Nacional do Cinema. Dados sistematizados pelo autor. 
exibição de filmes e os centros de consumo. Segundo dados da Ancine (2008: 55), 88,9\% das salas de exibição concentram-se nos shopping centers, contra apenas $11,1 \%$ que se localizam em lojas de rua.

0 crescimento do número de salas, além de ter ampliado o acesso dos brasileiros ao cinema, promoveu um acesso maior ao produto estrangeiro. Os dados revelam que houve aumento no número de espectadores dos filmes brasileiros durante o período, mas esse crescimento revela-se oscilante, enquanto o produto estrangeiro vê seu público aumentar de forma exponencial, com crescimento de 42\% durante a série histórica (Gráfico 4).

Apesar do crescimento no número de lançamentos de filmes lançados no mercado de salas de exibição (84\%), isso não representou uma presença maior dos filmes brasileiros no que concerne à sua taxa de penetração no mercado de salas de exibição ${ }^{12}$. A participação do produto nacional no mercado brasileiro manteve-se oscilante durante o período, em alguns momentos com presença inferior aos números apresentados antes do surgimento do FSA. É o caso do ano de 2003, em que a fatia de mercado do produto nacional chegou a 21,4\%, o maior nível dos últimos 17 anos. Em comparação percentual, o resultado de 2018 é 44\% menor em relação ao ano de 2003. Neste último, tinha-se um número menor de lançamentos nacionais em relação à série histórica, mas uma presença de mercado muito maior — resultado que nem a política do FSA conseguiu superar. Portanto, o impacto do fundo apresentou resultado positivo no que se refere ao incremento no segmento de produção de obras audiovisuais independentes, mas o alcance desse conteúdo permaneceu limitado ou pouco competitivo economicamente nas janelas de exibição.

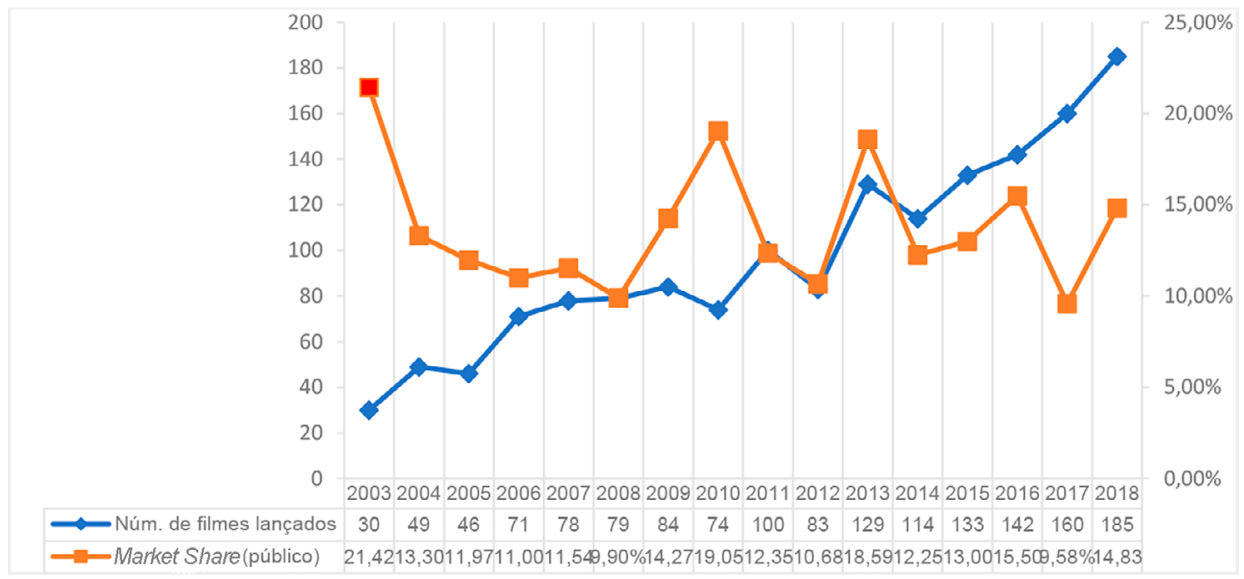

Gráfico 4 - Número de filmes lançados versus Market Share Público (\%) (2003-2018). Fonte: Observatório Brasileiro do Cinema e do Audiovisual/Agência Nacional do Cinema. Dados sistematizados pelo autor. 
Isso significa que a questão da autossutentabilidade econômica, baseada na retroalimentação sobre o retorno do investimento do FSA, acabou não se configurando da maneira inicialmente planejada. Segundo a Ancine: "Desde a sua primeira edição e até 31 de dezembro de 2017, o FSA obteve uma recuperação de R\$ 41.429.631,45". Os dados não são completos e totalmente fidedignos, mas mesmo assim nos informam que a conta no setor de produção em relação aos valores investidos não fecha. Entretanto, a caraterística de retroalimentação preconizada pelo FSA não busca a lucratividade financeira, já que sua principal missão é a indução do desenvolvimento. A acepção unicamente econômica não dá conta da totalidade da política. O lucro social do FSA é pouco abordado até mesmo por alguns autores que se propõem a estudar o campo. Há de se pensar o retorno de tal política sob variadas dimensões.

Se no segmento de salas de exibição a evolução foi apenas parcial, no mercado de televisão por assinatura os avanços são mais substanciais. Com a implementação das cotas televisivas (de programação e de empacotamento) ${ }^{13}$, houve aumento no número de obras brasileiras exibidas nos canais, uma mudança na dinâmica de negócios e no consumo do produto que pode contribuir para a formação de outra cultura visual. Vamos aos dados do Gráfico 5.

Segundo dados da Ancine, em 2009, a produção brasileira ocupava cerca 1,4\% do espaço de programação dos canais de espaço qualificado ${ }^{14}$. Os dados disponíveis são lacunares e foram apresentados em documento relativo ao ano de 2016. Com base em dados do Observatório Brasileiro do Cinema e do Audiovisual (OCA), que tem como ano inicial 2012, vemos essa taxa crescer exponencialmente em função do início da vigência da cota, com a obrigação de carregamento de 2 h20 de conteúdo brasileiro.

Apesar do aumento do licenciamento de obras nacionais no segmento, a presença do produto estrangeiro, assim como no mercado de salas de exibição, é predominante. Segundo o relatório Informe de Televisão Paga (Ancine, 2019): “A produção estrangeira manteve sua

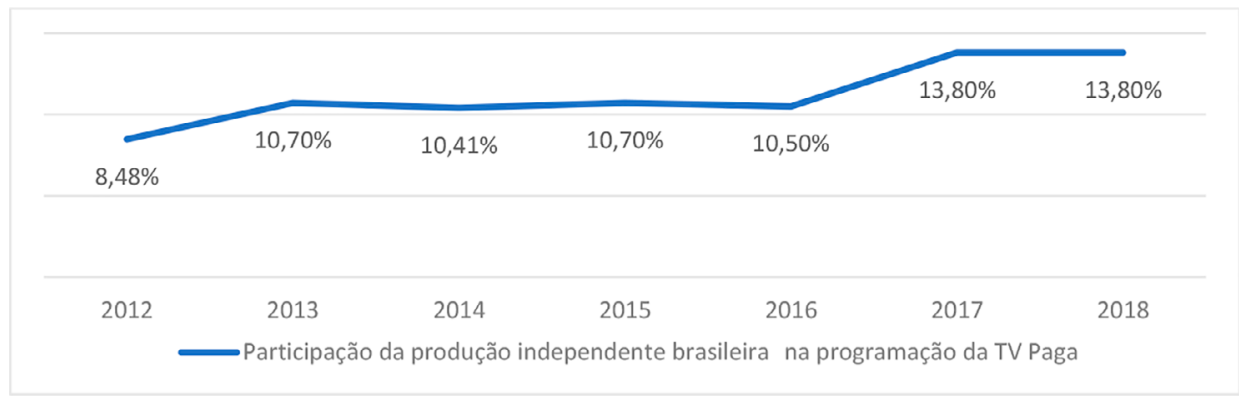

Gráfico 5 - Participação da produção independente brasileira na programação da televisão paga. Fonte: Observatório Brasileiro do Cinema e do Audiovisual/Agência Nacional do Cinema. Dados elaborados pelo autor. 
posição dos anos anteriores, permanecendo como a maior provedora de conteúdo qualificado da TV Paga, com 55,4\% de sua programação total (70,5 horas semanais)" ${ }^{15}$.

Tal cenário demonstra que o segmento da televisão por assinatura parece sofrer do mesmo mal que acomete o segmento cinematográfico: a presença tímida, garantida apenas por reserva de mercado da produção nacional, e a predominância do produto estrangeiro.

Para os agentes do mercado, mesmo a garantia mínima da presença no segmento, somada aos incentivos do fundo, representou uma revolução na economia do audiovisual nacional. Ana Rosa Tendler, produtora executiva da Caliban Cinema e Conteúdo, relata que antes do FSA "havia as leis de incentivo e muito balcão" — nomenclatura esta que ficou conhecida por representar uma política de fomento em que se levava mais em conta as relações interpessoais do produtor do que a qualidade do projeto em si. Com a chegada do FSA, além do crescimento dos recursos, ampliou-se também o leque de relações econômicas do setor. Retornando ao depoimento da produtora, fica claro que a percepção na ponta da política é a de que a situação mudou:

Tivemos uma reunião com um representante do canal CURTA! Ele gostou de um projeto nosso de série e eu percebi que a gente poderia ter um potencial de começar a produzir para a TV com o dinheiro do FSA. Antes era voltado muito para o cinema. Mas começamos a entender que tínhamos uma perspectiva de fazer o trabalho que a gente gostava de fazer, só que em uma outra janela. E aí essa porta foi aberta no Canal Curta! Depois abrimos uma porta no Cine Brasil TV que é [Canal Brasileiro de Espaço Qualificado] CABEQ também, outro canal dedicado à produção independe. Não tivemos que mudar nada que a gente já fazia. Só ampliamos as possiblidades das histórias que queríamos contar. 0 FSA tinha muito dinheiro e tinha a curadoria do canal, se o canal se interessasse, era quase um investimento certo. Pois é o canal que fazia a curadoria desse conteúdo. (Tendler, entrevista, 2020).

A relação econômica mais setorializada mitigou um pouco a lógica das leis de incentivo e estabeleceu o primado da relação baseada na qualidade do conteúdo, da parceria econômica entre empresas que primam pelo conteúdo competitivo, com impactos em sua própria dinâmica, pois elas se viram obrigadas a se aperfeiçoar para dar conta das mudanças que o Fundo trazia:

Com a aprovação da lei 12.485 na qual se amplia a quantidade de conteúdo obrigatório, quando se trazem novos players, programadores brasileiros, brasileiros independentes e estrangeiros. Você não só cria fortemente nova demanda de obras e conteúdo de qualidade, há uma disputa de programadores para ter conteúdos brasileiros. E isso demanda uma busca de conteúdo específicos. E aí você coloca novos players construindo e recolhendo o CIDE e desafia o setor. Uma ascensão muito positiva de produtoras nessa época. Produtoras mudando de porte, de qualidade, entrega, rapidez, de formação no sentido de profissionalização, não só no sentido da 
entrega, mas no sentido da burocracia nas próprias produtoras no que concerne à negociação de direitos financeiros das produtoras. Acontece uma revolução cotidiana no mercado com um impacto positivo no fundo. (Alcântara, entrevista, 2020).

Entre 2006 e 2018, a criação de uma política de fundo para o setor audiovisual inaugurou um novo capítulo no que Bahia (2012) denomina de "processos de industrialização" do audiovisual. Esse período trouxe uma série de acontecimentos inéditos para o audiovisual e reconfigurou política, econômica e financeiramente o setor, colocando-o num patamar muito diferente do que vimos no período anterior ao do objeto desta pesquisa. Rosana Alcântara, elaborando um balanço do período para esta pesquisa, ressalta, sobre o FSA, que:

0 Fundo é responsável por parte significativa do legado desta última década de toda a produção audiovisual brasileira independente, na TV, na internet e no cinema. Ele é responsável por apoiar o funcionamento e o cumprimento da política de cotas em $100 \%$ da produção. Ele é responsável por agregar recursos da capacitação de boa parte da cadeia produtiva. Ele é responsável por todo o processo de digitalização no Brasil, com foco em médios e pequenos e alguns grandes grupos. É responsável pela capacidade de regionalização da produção, porque através do dinheiro do FSA, as secretarias municipais aportaram recursos durante anos para que a produção regional acontecesse. Junto com a produção regional e com as salas, o Fundo deu conta da atração de novos recursos privados, o aporte do Fundo dá segurança para que a iniciativa provada aporte recursos. Eu diria que, se não houvesse uma lei, não houvesse um decreto, não houvesse uma governança, não houvesse um [Banco Regional de Desenvolvimento do Extremo Sul] BRDE, não houvesse um setor por trás, isso já teria sido desmontado. (Alcântara, entrevista, 2020).

\section{CONSIDERAÇÕES FINAIS}

1 extensão das características das variáveis da atividade audiovisual tornou necessária, do mercado. Esse olhar interior revelou que a problemática da atividade audiovisual não se dava apenas em uma relação entre cineastas e a luta contra o estrangeiro ou com a garantia do filme na sala, mas também pela totalidade da diversidade de segmentos que compõem o setor, da necessidade de se pensar a questão empresarial e, em última instância, de se ter uma visão mais total de como funciona a produção audiovisual no Brasil.

Vimos que as políticas implementadas no século XXI possuem como característica principal um entendimento da atividade com base no conceito de setor econômico. Tal compreensão deu-se mediante a necessidade de construção de uma nova política de fomento no âmbito do Estado, em consonância com a articulação entre os agentes econômicos da cadeia. 
Historicamente, as políticas públicas brasileiras para a área da produção audiovisual e da mídia em geral não conseguiram (às vezes não desejaram) fazer frente à presença da produção internacional no mercado brasileiro, ainda que a maioria dos diferentes atores sociais que aí atuaram desejassem uma maior autonomia e capacidade de mercado para o produto nacional. Tendo em vista que, contemporaneamente, as imagens competem pelo monopólio das representações, a ausência de regulações que discutam e garantam um acesso razoavelmente diverso e democrático aos conteúdos veiculados, em última instância, coloca em risco a diversidade cultural do país.

Buscando responder a algumas dessas questões, a área do audiovisual lançou mão do fundo setorial como sua principal ferramenta política. 0 conceito de setorialidade serviu-nos, aqui, como modelo de compreensão para analisar as relações específicas da cadeia produtiva do audiovisual. A política cultural praticada sob o conceito de setorial proporcionou uma mudança conceitual no entendimento da atividade, redesenhando o setor pelo caminho da diversificação, ainda que contenha traços de concentração dos investimentos em um perfil específico de produtoras, que, como vimos, tinham de ter postura empresarial. Apesar disso, trouxe igualmente um grande volume de recursos e criou ações com base no entendimento setorial de alocação de recursos conjuntos e sistêmicos nos diversos segmentos da cadeia.

Apesar de todos esses ganhos, a pesquisa salientou que a política setorial também possui fragilidades que limitam sua atuação. 0 programa de infraestrutura investiu na retomada e manutenção do crescimento do parque exibidor. Mesmo tendo alcançado um resultado aquém do total planejado incialmente, conseguiu devolver o parque exibidor a patamares iguais aos dos anos 1970. Apesar dessa vitória, os investimentos nesse segmento não lograram êxito em fazer com que as empresas exibidoras mudassem sua relação com os filmes brasileiros. 0 aumento no número de salas representou igualmente o incremento do consumo do produto norte-americano. Por mais que o Proinfra tenha conseguido promover o aumento do total de salas e diminuído a concentração geográfica, não conseguiu inserir de forma competitiva o filme nacional nas salas.

No mercado de televisão fechada, os avanços são mais claros. A Lei n 12.485 foi capaz de promover uma integração financeira e mercadológica inédita entre os agentes, ampliando dessa forma o mercado. As produtoras passaram a produzir mais conteúdo. Os canais, por conta das cotas, passaram a produzir com recursos do fundo novos e mais conteúdos juntamente com as produtoras. 0 impacto de tais alterações na regulação da produção audiovisual brasileira, nos campos da produção simbólica e da formação do imaginário nacional, talvez possa começar a ser analisado em estudos de consumo e recepção que venham a ser desenvolvidos. 
A partir de 2016, alguns acontecimentos no campo político/social provocaram uma mudança de rumo na condução da política audiovisual brasileira, colocando em xeque o projeto construído com base no FSA. Dois acontecimentos foram seminais para deflagrar o sinal amarelo entre os agentes do setor: o impeachment de Dilma Rousseff, que resultou na posse do presidente interino Michel Temer, e a vitória de Jair Bolsonaro nas eleições presidenciais de 2018.

O impeachment de Dilma fez surgir a oportunidade, para o grupo político que assumiu a gestão federal, de definir os dirigentes da Ancine, o Ministro da Cultura, entre outros cargos que possuem poder de condução e construção de políticas e ações públicas, e, portanto, de alterar os rumos das políticas para o setor audiovisual e cultural. É importante salientar que esse era um grupo que não estava no núcleo duro da construção da política audiovisual até então. Com o fim do mandato de Manuel Rangel na presidência da Ancine (ele havia sido colocado no cargo durante a gestão do Partido dos Trabalhadores - PT) e a consequente posse do escolhido do governo interino para o mesmo cargo, Christian de Castro, iniciou-se o processo de rompimento do chamado "pacto". Esse acordo era uma espécie de consenso silencioso entre os agentes que construíram e articularam a política e os agentes econômicos do setor, que arrefeceu possíveis diferenças políticas quanto ao rumo das políticas audiovisuais do período, principalmente no que concernia à utilização do FSA e à distribuição dos recursos no setor.

Uma das ações práticas configuradas pela chegada de Christian de Castro e que caracterizam a mudança de rumo da política audiovisual foi a criação do chamado FSA 2.0. Essa ação foi uma iniciativa que alterou o regulamento geral de utilização do fundo, criando uma nova estrutura normativa, novas regras de investimento, e extinguindo e criando linhas de ação. Os argumentos que justificaram essas mudanças se inserem na questão da desburocratização dos processos, de um foco maior no desempenho comercial das empresas e na infraestrutura tecnológica voltada ao campo dos efeitos especiais e de pós-produção. As mudanças também incluíram o segmento dos jogos eletrônicos (games) no ecossistema do audiovisual.

É importante salientar que a chegada dos games no espectro da política audiovisual deu-se somente no campo do fomento, sem de fato ter sido construída uma legislação que regulasse e normatizasse esse mercado (por exemplo, não há nenhuma normativa que obrigue os games comercializados no país a virem com legendas ou dublagem) ou que incluísse 0 segmento no pagamento do Condecine. Quem fornece os recursos que garantem a política de financiamento do segmento, por enquanto, são os filmes, as séries, os cinemas, as empresas de telecomunicações e os canais de televisão.

Em 2019 ocorreu uma reviravolta, com danos na imagem da Ancine e no setor audiovisual. 0 diretor-presidente Christian de Castro caiu em desgraça ao ser afastado do cargo 
sob acusação de crimes contra o sistema financeiro nacional, lavagem de dinheiro e atuação indevida no cargo, com supostas evidências de privilegiar certos agentes e grupos do setor audiovisual em detrimento de outros e de promover um dossiê acusatório contra outros diretores da Ancine (Debora Ivanov e Alex Braga Muniz) ${ }^{16}$. Tal fato revela que a instabilidade política chegou ao audiovisual, com disputas internas no cerne do campo e grupos querendo implementar projetos diferentes para o setor audiovisual.

Um segundo marco da mudança política que se vinha conflagrando até então foi a vitória de Jair Bolsonaro nas eleições de 2018 para o cargo de presidente da República. De início, há um movimento do governo Bolsonaro com o intuito de questionar o conteúdo dos filmes financiados pela agência ("Não admito ver filmes como Bruna Surfistinha sendo apoiados com dinheiro público. " ${ }^{17}$ e de investir no estabelecimento de critérios que restringissem a natureza do conteúdo dos projetos, sem levar em conta a sua qualidade técnica ou relevância artística ou comercial: "Se não puder ter filtro, nós extinguiremos a Ancine" ${ }^{18}$.

Há uma iniciativa de desconfiar das políticas construídas e dos projetos financiados até então, lançando mão de um discurso que deflagra a produção audiovisual nacional como inadequada. Nesse sentido, a natureza do conteúdo das obras audiovisuais e as suas potencialidades comerciais deveriam enquadrar-se conforme critérios ou crivos preconizados pelo governo federal. Essa centralização do poder de decisão quanto à natureza do conteúdo do investimento revela-se como um dado novo na política do FSA.

0 fato é que os investimentos do FSA estão paralisados, e houve até estudos para retirar a administração do FSA da alçada da Ancine e colocá-la sob o Ministério da Cidadania, no qual o órgão poderia ser mais bem controlado pelo governo federal. Por fim, a Ancine foi realocada para o Ministério do Turismo, vinculada à Secretaria Especial da Cultura (Secult). 0 que se percebe na primeira metade do governo Bolsonaro (2018-2020) é uma desidratação das políticas (ofensiva por meio de projeto de lei, com previsão de cortes de $43 \%$ dos investimentos do FSA em 2020 e a disputa em torno da revogação da Lei do Serviço de Acesso Condicionado — SeAC), das ações e das instituições (cancelamento de editais, a ocupação da presidência da Ancine por um interino), sem de fato acabar com elas, nem tampouco colocar algo no lugar. Tal postura mostra-se extremamente danosa ao setor audiovisual brasileiro. A produção audiovisual brasileira estava paralisada até mesmo antes da chegada da pandemia da COVID-19.

A batalha pela continuidade da política construída com base no FSA parece ter-se iniciado: "Ancine e o FSA foram criados por leis. Vamos ao Congresso!" 19, declara Mariza Leão, a produtora do longa-metragem De pernas pro ar, um dos maiores sucessos do investimento do FSA. A paralisia das ações do fundo representa um gatilho que os produtores audiovisuais conhecem bem e que ressuscita a eterna sina do campo: será este o fim de mais um ciclo do audiovisual brasileiro? 
Conflitos de interesse: nada a declarar.

Fonte de financiamento: nenhuma.

Contribuições dos autores: Calabre, L.; Tavares, T. S.: Administração do Projeto, Análise

Formal, Conceituação, Escrita - Revisão e Edição, Metodologia. Tavares, T. S.: Curadoria de Dados, Escrita - Primeira Redação, Software, Investigação. Calabre, L.: Supervisão, Validação e Visualização.

\section{NOTAS}

10 que se vê é uma sociedade totalmente visual, imposta por um regime de multiplicação de telas, uma sociedade ela mesma produtora de imagens em movimento, que filma a si mesma, que transformou o cinema em algo mais do que arte ou indústria. Se hoje nós somos "documentaristas de nós mesmos" nas redes sociais, isso é consequência de uma relação transversal com o cinema.

2 Não trataremos no escopo desta pesquisa do mercado de televisão aberta por ele não estar no campo de regulamentação da Ancine.

3 Há de se pensar fundamentalmente acerca de uma política de colonização do olhar na cultura visual promovida pela indústria cultural estrangeira.

40 curta-metragem deixou até mesmo de ser critério de pontuação para a seleção de investimento por meio do FSA desde 2015, deixando muitos produtores distantes em relação às empresas já estabelecidas.

5 Não há como deixar de citar a trágica ameaça do fechamento vivida pela Cinemateca Brasileira.

6 Com esse movimento, cria-se o que se convencionou chamar de canais "superbrasileiros", que veiculam 12 horas de produção independente brasileira, e canais "superindependentes", ou avulsos (Lima, 2015).

7 Importante considerar que há uma diferença entre os valores arrecadados e os valores efetivamente investidos no setor.

8 Procurado para dar esclarecimentos sobre essa posição, o SindiTelebrasil (Sindicato Patronal das Empresas de Telecomunicações) respondeu que não seria possível ceder uma entrevista para esta pesquisa.

9 "[...] o Ministério da Fazenda autorizou um reajuste de quase 28,5\% no valor da taxa, 0 que fez com que as empresas buscassem uma saída jurídica para evitar um aumento estimado 
em R\$ 200 milhões na contribuição anual". Disponível em: <https://www.convergenciadigital.com.br/cgi/cgilua.exe/sys/start.htm? UserActiveTemplate=site\&UserActiveTemplate=mobile\&infoid=41620\&sid=8>. Acesso em: 19 mar. 2020.

10 "Para ministro, argumento das teles para não pagar Condecine é 'ridículo'". Disponível em: <https://oglobo.globo.com/cultura/para-ministro-argumento-das-teles-para-nao-pagar-condecine-ridiculo-18743399 >. Acesso em: 19 mar. 2020.

110 declínio do parque exibidor inicia-se com a chegada do home video, que representou um forte concorrente para as salas de cinema, da crise econômica que se abateu sobre o país a partir do fim da década de 1970 e início dos anos 1980 (a chamada década perdida) e da antipolítica audiovisual promovida pelo governo Collor. Segundo dados disponíveis no site Filme B, a resseção do segmento exibidor acentuou-se durante os anos de 1990, quando recuou a um patamar de apenas 1.033 salas.

12 Termo conhecido como market share.

13 A lei $n^{0} 12.485$ reconfigurou o entendimento conceitual dos canais de programação e dividiu-os por tipos: Canal de Espaço Qualificado (CEQ), Canal Brasileiro de Espaço Qualificado (Cabeq), Canal Brasileiro Independente de Espaço Qualificado (Cabeqi), Canal Super Brasileiro (SB) e Canal Super Brasileiro Independente (SBsR)

14 "Muito vale o já feito. Mais vale o que será". Disponível em: <https://www.ancine.gov. br/sites/default/files/apresentacoes/Apresenta\%C3\%A7\%C3\%A30\%20RCM\%202017\%20 3.2.pdf>. Acesso em: 23 abr. 2020.

15 Televisão Paga 2018. Disponível em <https://oca.ancine.gov.br/sites/default/files/repositorio/pdf/tv_paga.pdf>. Acesso em: 22 abr. 2020.

16 Para mais informações, consultar: "Christian de Castro e a loteria premiada da Ancine". Disponível em: <https://farofafa.cartacapital.com.br/2019/09/28/christian-de-castro-e-a-loteria-premiada-da-ancine/>. Acesso em: 17 nov. 2020.

17 "Bolsonaro diz que vai acabar com a Ancine se não puder impor mecanismos de censura". Disponível em: <https://revistaforum.com.br/politica/bolsonaro/bolsonaro-diz-que-vai-acabar-com-a-ancine-se-nao-puder-impor-mecanismos-de-censura/>. Acesso em: 20 abr. 2020.

18 ldem.

19 "Fim da Ancine? 0 que pode acontecer com os filmes e séries nacionais". Disponível em: $<$ https://entretenimento.uol.com.br/noticias/redacao/2019/08/02/fim-da-ancine-o-que-pode-acontecer-com-os-filmes-e-series-nacionais.htm?cmpid=copiaecola>. Acesso em: 30 abr. 2020. 


\section{REFERÊNCIAS BIBLIOGRÁFICAS}

ANCINE - Agência Nacional do Cinema. Fundo Setorial do Audiovisual: documento de diretrizes. Rio de Janeiro: Ancine, s/d.a. Disponível em: <https://fsa.ancine.gov.br/programas/introducao>. Acesso em: 26 maio 2016.

ANCINE - Agência Nacional do Cinema. Prodecine - Programa de Apoio ao Desenvolvimento do Cinema Brasileiro. Rio de Janeiro: Ancine, s./d.b. Disponível em: <http://fsa.ancine.gov.br/programas/prodecine>. Acesso em: 26 maio 2016.

ANCINE - Agência Nacional do Cinema. Programa Integrado do Parque Exibidor. Rio de Janeiro: Ancine, s./d.c. Disponível em: <http://cinemaperto devoce.ancine.gov.br>. Acesso em: 25 maio 2016.

ANCINE - Agência Nacional do Cinema. Relatório Anual de Gestão do Fundo Setorial do Audiovisual - FSA. Exercício de 2008. Rio de Janeiro: Ancine, s./d.d.

ANCINE — Agência Nacional do Cinema. Relatório Anual de Gestão do Fundo Setorial do Audiovisual - FSA. Exercício de 2011. Rio de Janeiro: Ancine, s./d.e.

ANCINE - Agência Nacional do Cinema. Relatório de Gestão do Fundo Setorial do Audiovisual - FSA. Exercício de 2009. Rio de Janeiro: Ancine, 2010.

ANCINE - Agência Nacional do Cinema. Relatório Anual de Gestão do Fundo Setorial do Audiovisual - FSA. Exercício de 2010. Rio de Janeiro: Ancine, 2011.

ANCINE - Agência Nacional do Cinema. Relatório Anual de Gestão do Fundo Setorial do Audiovisual - FSA Exercício de 2012. Rio de Janeiro: Ancine, 2013a.

ANCINE - Agência Nacional do Cinema. Plano de diretrizes e metas para o audiovisual: o Brasil de todos os olhares para todas as telas. 1. ed. Rio de Janeiro: Ancine, 2013b.

ANCINE - Agência Nacional do Cinema. Plano de diretrizes e metas para o audiovisual: o Brasil de todos os olhares para todas as telas. Rio de Janeiro: Ancine, 2013c.

ANCINE - Agência Nacional do Cinema. Relatório Anual de Gestão do Fundo Setorial do Audiovisual - FSA Exercício de 2013. Rio de Janeiro: Ancine, 2014.

ANCINE - Agência Nacional do Cinema. Relatório Anual de Gestão do Fundo Setorial do Audiovisual - FSA. Exercício de 2014. Rio de Janeiro: Ancine, 2015.

ANCINE - Agência Nacional do Cinema. Relatório Anual de Gestão do Fundo Setorial do Audiovisual - FSA. Exercício de 2015. Rio de Janeiro: Ancine, 2016.

ANCINE - Agência Nacional do Cinema. Relatório Anual de Gestão do Fundo Setorial do Audiovisual - FSA. Exercício de 2016. Rio de Janeiro: Ancine, 2017.

BAHIA, L. Discursos, políticas e ações: processos de industrialização do campo cinematográfico brasileiro. São Paulo: Itaú Cultural, 2012.

BRASIL. Medida Provisória n 2.228-1, de 6 de setembro de 2001. Estabelece princípios gerais da Política Nacional do Cinema, cria o Conselho Superior do Cinema e a Agência Nacional do Cinema - ANCINE, institui o Programa de Apoio ao Desenvolvimento do Cinema Nacional — PRODECINE, autoriza a criação de Fundos de Financiamento da Indústria Cinematográfica Nacional — FUNCINES, altera a legislação sobre a 
Contribuição para o Desenvolvimento da Indústria Cinematográfica Nacional e dá outras providências. Diário Oficial da União, Brasília, DF, 10 set. 2001. Disponível em: <http://www.planalto.gov.br/ccivil_03/MPV/22281.htm\#art47>. Acesso em: 15 nov. 2020.

BRASIL. Lei $n^{0}$ 11.437, de 28 de dezembro de 2006. Altera a destinação de receitas decorrentes da Contribuição para o Desenvolvimento da Indústria Cinematográfica Nacional - CONDECINE, criada pela Medida Provisória $n^{\circ}$ 2.228-1, de 6 de setembro de 2001, visando ao financiamento de programas e projetos voltados para o desenvolvimento das atividades audiovisuais; altera a Medida Provisória $\mathrm{n}^{\circ}$ 2.228-1, de 6 de setembro de 2001, e a Lei $n^{\circ} 8.685$, de 20 de julho de 1993, prorrogando e instituindo mecanismos de fomento à atividade audiovisual; e dá outras providências. Diário Oficial da União, Brasília, DF, 29 dez. 2006. Disponível em: <http://www.planalto.gov.br/ccivil_03/_ato2004-2006/2006/lei//11437. htm>. Acesso em: 15 nov. 2020.

BRASIL. Decreto $n^{\circ} 6.299$, de 12 de dezembro de 2007. Regulamenta os arts. $1^{\circ}, 2^{\circ}, 3^{\circ}, 4^{\circ}, 5^{\circ}$ e $6^{\circ}$ da Lei $n^{\circ} 11.437$, de 28 de dezembro de 2006, que destinam recursos para o financiamento de programas e projetos voltados para o desenvolvimento das atividades audiovisuais, e dá outras providências. Diário Oficial da União, Brasília, DF, 13 dez. 2007. Disponível em: <http://www.planalto.gov.br/ccivil_03/_ato20072010/2007/decreto/D6299>. Acesso em: 25 nov. 2020.

BRASIL. Fundo Setorial do Audiovisual. Rio de Janeiro: Ancine, 2008. Disponível em: <https://fsa.ancine.gov. br/sites/default/files/prospectos-e-apresentacoes/FSA>. Acesso em: 23 nov. 2020.

BRASIL. Lei $n^{0} 12.485$, de 12 de setembro de 2011. Dispõe sobre a comunicação audiovisual de acesso condicionado; altera a Medida Provisória $n^{\circ} 2.228-1$, de 6 de setembro de 2001, e as Leis $n^{\circ} \mathrm{s} 11.437$, de 28 de dezembro de 2006, 5.070, de 7 de julho de 1966, 8.977, de 6 de janeiro de 1995, e 9.472, de 16 de julho de 1997; e dá outras providências. Diário Oficial da União, Brasília, DF, 13 set. 2011. Disponível em: <http:// www.planalto.gov.br/ccivil_03/_Ato2011-2014/2011/Lei/L12485.htm>. Acesso em: 15 nov. 2020.

FINEP - Financiadora de Estudos e Projetos. O que são fundos setoriais. Rio de Janeiro: Finep, 2016. Disponível em: <http://www.finep.gov.br/a-finep-externo/fndct/estrutura-orcamentaria/o-que-sao-os-fundossetoriais>. Acesso em: 15 nov. 2020.

LIMA, H. S. A Lei da TV Paga: impactos no mercado audiovisual. 2015. Tese (Doutorado) - Universidade de São Paulo, São Paulo, 2015.

MARTINS, V. A. P. Fundamentos da atividade cinematográfica e audiovisual: teoria e questões. Rio de Janeiro: Elsevier, 2009.

MIRZOEFF, N. Una introducción a la cultura visual. Barcelona: Paidós, 2003.

MONTEIRO, R. H. Cultura visual: definições, escopo, debates. Domínios da Imagem, Londrina, v. 1, n. 2, p. 129-134, 2008.

SOUSA, A. P. S. Dos conflitos ao pacto: as lutas no campo cinematográfico brasileiro no século XXI. 2018. 294 p. Tese (Doutorado) - Universidade Estadual de Campinas, Campinas, 2018.

\section{ENTREVISTAS}

ALCÂNTARA, Rosana dos Santos. [Entrevista cedida a] Thiago Tavares. São Gonçalo: 15 abr. 2020.

TENDLER, Ana Rosa. [Entrevista cedida a] Thiago Tavares. São Gonçalo: 18 abr. 2020. 